\title{
An Intronic Mutation in a Lariat Branchpoint Sequence Is a Direct Cause of an Inherited Human Disorder (Fish-Eye Disease)
}

\author{
Jan Albert Kuivenhoven, Heiko Weibusch, ${ }^{\star}$ P. Haydn Pritchard, ${ }^{\ddagger}$ Harald Funke, ${ }^{\star}$ Rob Benne, ${ }^{\S}$ Gerd Assmann, ${ }^{\star}$ \\ and John J.P. Kastelein \\ Department of Vascular Medicine, Academic Medical Center, University of Amsterdam, 1105 AZ Amsterdam, The Netherlands; *Institut \\ für Arterioskleroseforschung, Westphälische Wilhelms-Universität Münster, 48149 Münster, Germany; ${ }^{*}$ Atherosclerosis Specialty \\ Laboratory, Department of Pathology and Laboratory Medicine, St. Paul's Hospital \& University of British Columbia, Vancouver, \\ British Columbia, Canada, V5Z 4H4; and ${ }^{\S}$ Slater Institute for Biochemical Research, Academic Medical Center, University of Amsterdam, \\ 1105 AZ Amsterdam, the Netherlands
}

\begin{abstract}
The first step in the splicing of an intron from nuclear precursors of mRNA results in the formation of a lariat structure. A distinct intronic nucleotide sequence, known as the branchpoint region, plays a central role in this process. We here describe a point mutation in such a sequence. Three sisters were shown to suffer from fish-eye disease (FED), a disorder which is caused by mutations in the gene coding for lecithin:cholesterol acyltransferase (LCAT). Sequencing of the $L C A T$ gene of all three probands revealed compound heterozygosity for a missense mutation in exon 4 which is reported to underlie the FED phenotype, and a point mutation located in intron 4 (IVS4:T-22C). By performing in vitro expression of $L C A T$ minigenes and reverse transcriptase PCR on mRNA isolated from leukocytes of the patient, this gene defect was shown to cause a null allele as the result of complete intron retention. In conclusion, we demonstrated that a point mutation in a lariat branchpoint consensus sequence causes a null allele in a patient with FED. In addition, our finding illustrates the importance of this sequence for normal human mRNA processing. Finally, this report provides a widely applicable strategy which ensures fast and effective screening for intronic defects that underlie differential gene expression. (J. Clin. Invest. 1996. 98:358364.) Key words: intron retention • splicing • genetic disease - HDL deficiency • lecithin:cholesterol acyltransferase
\end{abstract}

\section{Introduction}

To date, the search for mutations as the cause of human genetic disease is mainly confined to the promoter region, coding sequences, and intron-exon boundaries of the gene under scrutiny. However, this strategy proved to be unsuccessful in an attempt to elucidate the genetic background of a case of

Portions of this work were presented in abstract form at the 68th International Symposium of the American Heart Association in Anaheim on 13-16 November 1995.

Address correspondence to Jan Albert Kuivenhoven, Department of Vascular Medicine (G1-114), Academic Medical Center, Meibergdreef 9, 1105 AZ Amsterdam, The Netherlands. Phone: 20 5665842; FAX: 20 6916972; E-mail: kuif@wnet.bos.nl

Received for publication 26 January 1996 and accepted in revised form 14 May 1996

J. Clin. Invest.

(C) The American Society for Clinical Investigation, Inc.

0021-9738/96/07/0358/07 \$2.00

Volume 98, Number 2, July 1996, 358-364 fish-eye disease (FED) ${ }^{1}$ a disorder which is caused by defects in the gene coding for lecithin:cholesterol acyltransferase (LCAT) (1-4). Only after extending our search for mutations further into noncoding DNA were we able to explain the biochemical and clinical phenotype of our index patient. We identified a point mutation in intron 4 of the LCAT gene which resides in a conserved lariat branchpoint sequence, a region which plays a central role in the splicing mechanism. The first step involved in the excision of an intron from pre-mRNA results in the formation of a lariat structure in which the binding of the U2snRNA to this branchpoint region of the pre-mRNA is a prerequisite $(5,6)$. The lariat formation is mediated by a nucleophilic attack at the $5^{\prime}$ splice site by the $2-\mathrm{OH}$ of an adenosine residue. This adenosine is located 10-50 nucleotides upstream of the $3^{\prime}$ splice site (7) in the context of a branchpoint consensus sequence that can basepair with U2snRNA $(5,8)$. Although much is known about the highly conserved branchpoint region in yeast, the knowledge of the far less conserved mammalian sequence is limited with regard to the requirements which ensure its use as a branchpoint in lariat formation and consequently correct splicing. In 1993, Rosenthal et al. (9) suggested an association between a mutation in a putative branchpoint region and the use of alternative splice sites in human pre-mRNA. We now provide unequivocal evidence that a mutation in such a sequence can cause intron retention and consequently results in a null allele.

\section{Methods}

Family history. The 52-year-old female index patient was seen in an outpatient clinic in 1986 because of left-sided abdominal pain and constipation. Endoscopy revealed no abnormalities and she was treated for irritable bowel disease. In the past she had consulted an ophthalmologist who diagnosed congenital cloudiness of both cornea which was also identified in two of her sisters. On physical examination by an internist, the only abnormal clinical finding was the cloudiness of the cornea of both eyes. None of the three sisters nor their family members were known to suffer from premature atherosclerosis.

Blood samples and isolation of genomic DNA. Blood from the index patient and her family members was collected in EDTA tubes after an overnight fast and placed immediately on wet ice. Plasma was separated from cells by centrifugation $\left(1,200 \mathrm{~g} ; 15 \mathrm{~min} ; 4^{\circ} \mathrm{C}\right)$, frozen in liquid nitrogen and stored at $-70^{\circ} \mathrm{C}$. Genomic DNA was extracted from white cells as described previously (10).

1. Abbreviations used in this paper: BHK, baby hamster kidney cells; CER, cholesterol esterification rate; FED, fish-eye disease; LCAT, lecithin:cholesterol acyltransferase; nd, not determined; r, recombinant; RT, reverse transcriptase; TC, total cholesterol; TG, triglycerides. 


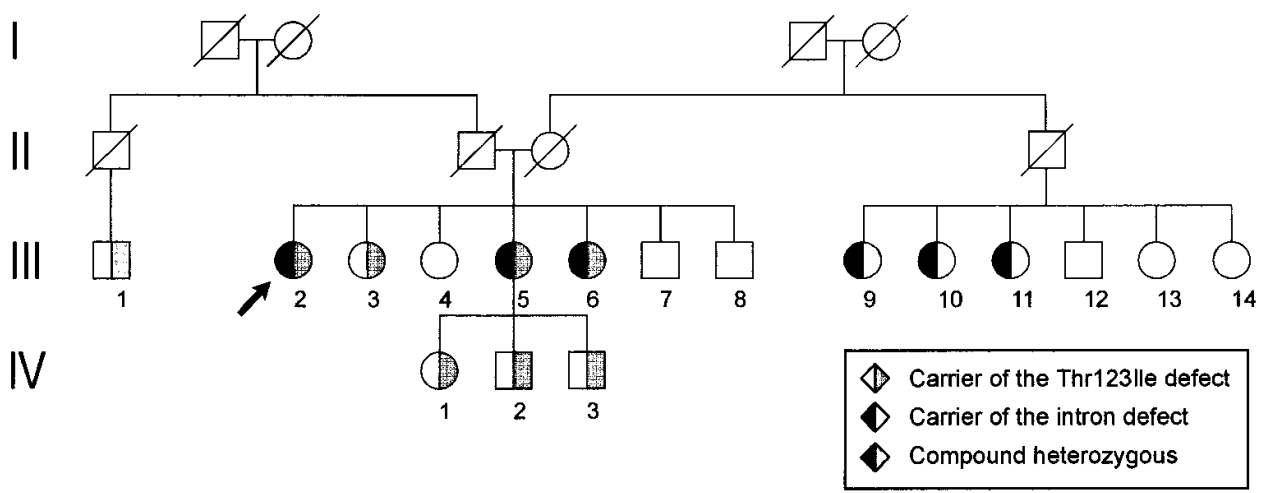

Figure 1. Pedigree of the kindred investigated. This figure includes the results of screening the DNA of family members for the presence of two point mutations, i.e., $\mathrm{C}^{2182}$ to $\mathrm{T}$ in exon 4 resulting in $\mathrm{T} 123 \mathrm{I}$, and $\mathrm{T}^{2327}$ to $\mathrm{C}$ in intron 4 , respectively. Squares and circles represent males and females, respectively. The arrow indicates the index patient. Right-sided shading (grey) indicates heterozygosity for T123I defect whereas left-sided shading (black) indicates heterozygosity for the intron mutation. Diagonal bar; deceased.
Lipid, lipoprotein, and apolipoproteins. Total cholesterol (TC) and triglycerides (TG) were determined enzymatically by established methods. HDL-cholesterol was determined as cholesterol remaining after precipitation of apo B-containing lipoproteins by phosphotungstate- $\mathrm{MgCl}_{2}$ and LDL-cholesterol was calculated using the Friedewald formula (11). Plasma apo A-I and apo B were measured by nephelometry.

LCAT activities, LCAT concentration, and cholesterol esterification rates $(C E R)$. LCAT activity was measured as described previously (12). LCAT mass was measured by radioimmunoassay by Dr. S.M. Marcovina (University of Washington School of Medicine; Seattle, WA) (13). CER were calculated from the rate of the esterification of $\left[{ }^{3} \mathrm{H}\right]$ cholesterol and plasma free cholesterol (FC) levels as described previously $(14,15)$.

Sequence analysis of the LCAT gene. Coding sequences, intronexon boundaries and complete introns 2, 3, and 4 including 400 bp upstream of exon 1 and 100 bp downstream of exon 6 were amplified by PCR followed by direct sequencing on a solid support (16). The genomic nucleotide sequences used to synthesize the primers were derived from McLean et al. (1986) (17). The 3' primers were labeled with biotin and fluorescent-labeled nested primers were used for sequencing. PCR was performed using 10 pmol nonbiotinylated and 5 pmol biotinylated primer in a total volume of $50 \mu$ l containing 0.1 $\mathrm{mmol} / \mathrm{liter}$ of each dNTP, $0.1 \mu \mathrm{g}$ genomic DNA, and 0.5 Units of SuperTaq DNA-polymerase (HT-Biotechnology Ltd., Cambridge, United Kingdom) in a buffered solution (50 mM KCl, $10 \mathrm{mM}$ Tris$\mathrm{HCl} ; \mathrm{pH} 9.5,1.5 \mathrm{mM} \mathrm{MgCl}_{2}, 0.1 \%$ Triton $\mathrm{X}, 0.01 \%$ gelatine). The reaction was carried out by using a Perkin Elmer GeneAmp PCR System 9600 (Perkin Elmer, Norwalk, CT) with an initial hot start technique (18) followed by a touchdown-PCR cycling protocol (19) with annealing temperatures dropping from 69 to $62^{\circ} \mathrm{C}$ within $40 \mathrm{cy}$ cles. To prepare single-stranded DNA, $35 \mu l$ paramagnetic beads (Dynabeads M-280, Dynal, Norway) were used as recommended by the supplier. The immobilized template was sequenced on an ALF Sequencer following the instruction of the autoread T7 Sequencing kit (both from Pharmacia Biotechnology, Sweden).

Mutagenic PCR for the detection of the intron base substitution. To investigate if the intron base substitution was present in the general population, we synthesized a $5^{\prime}$-mismatch primer with a $5^{\prime}$-AT-clamp that created a Sau961 restriction site in the presence of the intron base substitution: 5'-TAT TTA TTA TAT TTT ATA TTT AGT TTA TTA CAG GTG CCC CAG ACC CCA GCT GGC C-3' (the mismatch nucleotide is underlined). As a downstream primer we used: 5'-CGC AGC AGG AAA TAG AGC AAG TGT A-3'. The amplication reactions were carried out using $0.2 \mathrm{U}$ Supertaq and performing 30 amplification cycles: $45 \mathrm{~s} 95^{\circ} \mathrm{C} / 30 \mathrm{~s} 65^{\circ} \mathrm{C} / 30 \mathrm{~s} 72^{\circ} \mathrm{C}$. Using these PCR conditions, a single 204 bp DNA fragment was amplified from genomic DNA. $10 \%$ of the PCR product was used for digestion with $2 \mathrm{U}$ Sau961 in a total reaction volume of $20 \mu \mathrm{l}$ according to the manufacturer's instructions (New England Biolabs, Beverly, MA).
Products were analyzed on $2 \%$ agarose gel: the presence of the intron base substitution resulted in the generation of DNA fragments of 52 and $152 \mathrm{bp}$, respectively. The DNA of the index patient was used as a positive control in all assays.

Construction and expression of LCAT minigenes. A DNA fragment encompassing intron 4 of the LCAT gene was amplified by PCR from the genomic DNA of a compound heterozygote. Using unique restriction sites, the intron was inserted into wild type LCAT cDNA. These minigenes were ligated into the pNUT expression vector $(20,21)$ and part of the ligation mixture was used to transform E. coli. Colonies were selected for ampicillin resistance and plasmid DNA was isolated. By sequence analysis we identified clones that either contained wild type intron sequence (LCAT-Int4-WT) or an intron with the point mutation (LCAT-Int4-MUT). Correct minigene constructs were used to establish baby hamster kidney (BHK) cell lines (22). The identification of clones expressing recombinant (r)LCAT, the LCAT activity measurements, and the in vivo labeling experiments were carried out as described previously $(22,23)$.

Reverse transcriptase (RT)-PCR. The isolation of mRNA from the BHK cell lines and leukocytes of a compound heterozygote was performed using poly-dT magnetic beads (Dynal A.S., Oslo, Norway). Subsequent first-strand cDNA synthesis was carried out using a first-strand cDNA Synthesis Kit (Clontech Laboratories, Inc., Palo Alto, CA). After reverse transcription, $10 \%$ of the reaction product was used in a touch-down PCR (19) using specific LCAT oligonucleotides of which the lower strand primer was biotinylated. RT-PCR products were separated on a 3\% agarose gel and visualized with ethidium bromide. Direct sequence analysis, encompassing the intronexon boundaries of intron 3 and intron 4 , was performed using nested fluorescence primers as described above.

\section{Results}

Genetic analysis. Direct sequencing of the $L C A T$ gene of the index patient revealed heterozygosity for two point mutations: (a) a missense mutation in exon $4\left(\mathrm{C}^{2182}\right.$ to $\left.\mathrm{T}\right)$, resulting in the exchange of a Thr residue for a Ile at position 123 (T123I) of the mature protein, and $(b)$ a $\mathrm{T}$ to $\mathrm{C}$ substitution at position 2327 which unexpectedly was located in intron 4, 22 bases upstream of the acceptor splicing site. Two sisters of the index patient proved to be heterozygous for the same mutations and we identified four T123I carriers within the same family (Fig. 1). Screening of more distant family members revealed that the T123I defect originated from the father's side of the family whereas we identified three carriers of the intron mutation the other branch of the pedigree (Fig. 1). To investigate if the intron 4 base substitution was present in the general population, 


\begin{tabular}{|c|c|c|c|c|c|c|c|}
\hline Genetic status & Subject & $\mathrm{TC}$ & TG & LDL-c & HDL-c & apo A-1 & apo B \\
\hline & \multicolumn{5}{|c|}{ mmol/liter } & \multicolumn{2}{|c|}{$m g / d l$} \\
\hline \multicolumn{8}{|l|}{ Compound heterozygous } \\
\hline \multirow[t]{3}{*}{ for T123I/intron mutation } & III-2 & 8.43 & 9.80 & nd & 0.08 & $<25$ & 200 \\
\hline & III-5 & 4.96 & 4.71 & 2.31 & 0.05 & 26 & 146 \\
\hline & III-6 & 5.33 & 4.35 & 3.24 & 0.11 & 30 & 174 \\
\hline Mean \pm SD & & $6.2 \pm 1.6$ & $6.3 \pm 2.5^{*}$ & $2.8 \pm 0.5$ & $0.08 \pm 0.02$ & $19 \pm 13$ & $173 \pm 32$ \\
\hline \multirow[t]{5}{*}{ Heterozygous for T123I } & III-1 & 3.16 & 0.65 & 2.13 & 0.74 & 90 & 79 \\
\hline & III-3 & 5.04 & 1.79 & 3.13 & 1.10 & 147 & 85 \\
\hline & IV-1 & 4.61 & 1.53 & 2.94 & 0.97 & 132 & 92 \\
\hline & IV -2 & 3.60 & 0.95 & 2.34 & 0.83 & 98 & 63 \\
\hline & IV -3 & 2.98 & 0.94 & 1.91 & 0.64 & 81 & 58 \\
\hline Mean \pm SD & & $3.9 \pm 0.8^{\ddagger}$ & $1.2 \pm 0.4$ & $2.5 \pm 0.5^{\S}$ & $0.9 \pm 0.2$ & $110 \pm 25$ & $75 \pm 13$ \\
\hline \multirow[t]{3}{*}{ Heterozygous for intron mutation } & III-9 & 3.49 & 0.69 & 2.44 & 1.19 & 133 & 80 \\
\hline & III-10 & 4.50 & 2.77 & 2.69 & 0.56 & 84 & 125 \\
\hline & III-11 & 6.33 & 1.48 & 4.92 & 0.75 & 77 & 148 \\
\hline Mean \pm SD & & $4.9 \pm 1.0$ & $1.7 \pm 0.9$ & $3.4 \pm 1.1$ & $0.8 \pm 0.3$ & $98 \pm 25$ & $118 \pm 28$ \\
\hline \multirow[t]{6}{*}{ Normal } & III-4 & 5.04 & 0.84 & 2.79 & 1.87 & 203 & 72 \\
\hline & III-7 & 4.65 & 1.40 & 2.88 & 1.13 & 137 & 85 \\
\hline & III-8 & 6.10 & 1.38 & 4.19 & 1.28 & 161 & 106 \\
\hline & III-12 & 4.17 & 2.11 & 2.57 & 0.65 & 91 & 105 \\
\hline & III-13 & 6.24 & 2.66 & 4.11 & 0.94 & 110 & 153 \\
\hline & III-14 & 6.94 & 2.65 & 4.69 & 1.06 & 129 & 172 \\
\hline Mean \pm SD & & $5.5 \pm 1.0$ & $1.8 \pm 0.7$ & $3.5 \pm 0.8$ & $1.2 \pm 0.4$ & $139 \pm 36$ & $116 \pm 36$ \\
\hline
\end{tabular}

The status of family members was determined by DNA analysis. Data of heterozygotes for the T123I mutation were compared with unaffected family members using the Student's $t$ test: ${ }^{*} P<0.009 ;{ }^{\ddagger} P<0.024 ;{ }^{\S} P<0.047$. Note: subject III-10 was not fasted.

we designed a mismatch PCR to screen for this mutation. We failed to identify this mutation in a group of 98 unrelated subjects with plasma HDL-cholesterol below the $10^{\text {th }}$ percentile for age and sex and 70 additional normolipidemic controls which illustrates that this mutation is not a common variant of the LCAT gene.

Lipid, lipoprotein, and apolipoproteins. The results of lipid, lipoprotein and apolipoprotein analysis are shown in Table I. The three compound heterozygous sisters were characterized by severely reduced plasma HDL-cholesterol and apo A-I. In addition, they presented with high apo B levels and significantly elevated TG levels $(P<0.009)$ as compared with unaffected family members.

Heterozygotes for either the T123I defect or the intron mutation presented with low normal HDL-cholesterol and apo A-I. By contrast, only T123I carriers exhibited significantly lower TC and LDL-cholesterol as compared with unaffected controls and moderately reduced apo $\mathrm{B}$.

LCAT activities, LCAT concentration, and CER. LCATrelated parameters are presented in Table II whereby LCAT activity represents the ability of plasma to esterify cholesterol in an exogenously presented HDL-analogue substrate and the CER reflects the esterification of cholesterol within the endogenous lipoproteins of the plasma. The probands showed a near total loss of plasma LCAT activity, markedly reduced plasma LCAT concentration and residual specific LCAT activities. Irrespective of the loss of activity against HDL-analogues, their plasma LCAT was still able to generate cholesterol esters as shown by the low normal CERs.
Heterozygotes for either the T123I defect or the intron mutation exhibited significantly reduced LCAT activity as compared to family controls although subject III-9 presented with low normal LCAT activity. In addition, heterozygotes for either mutation showed low normal CERs. Furthermore, plasma LCAT concentrations were high normal in carriers of the T123I defect whereas heterozygotes for the intron mutation exhibited significantly reduced LCAT concentrations $(P<$ 0.0008) as compared with unaffected controls.

In vitro analysis of the intron mutation. To study the effect of the intron mutation on the expression of the LCAT gene in vitro, we stably transfected BHK cells with LCAT minigene constructs: full-length wild-type cDNAs containing intron 4 with either a thymine or cytosine at position 2327 (LCATInt4-WT and LCAT-Int4-MUT, respectively) (Fig. 2 A). After stable transfection, we screened for the presence of LCAT cDNA in the genome of the cell lines by Southern blotting and confirmed the presence of LCAT cDNA in both minigene cell lines with an approximately equal copy number. By contrast, we failed to identify LCAT cDNA in a cell line transfected with an empty pNUT vector (data not shown).

Media from both cell lines were harvested and assayed for LCAT activity and LCAT concentration. In contrast to the BHK cells which were transfected with the wild-type minigene, we could not detect LCAT activity nor LCAT mass in the culture medium harvested from the LCAT-Int4-MUT cell line (Fig. $2 A$ ). The lack of synthesis and secretion of LCAT protein by cells expressing the mutant minigene was confirmed by in vivo labeling experiments (Fig. $2 \mathrm{~B}$ ). In addition, we re- 
Table II. LCAT Activity, LCAT Concentration, and CER

\begin{tabular}{|c|c|c|c|c|c|}
\hline Genetic status* & Subject & LCAT activity & LCAT concentration & Specific activity & CER \\
\hline & & nmol/h.ml & $\mu g / m l$ & nmol/h. $\mu g$ & nmol/h.ml \\
\hline \multicolumn{6}{|l|}{ Compound heterozygous for } \\
\hline \multirow[t]{3}{*}{ T123I/intron mutation } & III-2 & 1.40 & 2.62 & 0.53 & 91 \\
\hline & III-5 & 1.16 & 1.79 & 0.65 & 87 \\
\hline & III-6 & 1.10 & nd & - & 74 \\
\hline Mean \pm SD & & $1.2 \pm 0.1$ & $2.2 \pm 0.4$ & $0.6 \pm 0.06$ & $84 \pm 7$ \\
\hline \multirow[t]{5}{*}{ Heterozygous for T123I } & III-1 & nd & nd & nd & nd \\
\hline & III-3 & 19.7 & 5.21 & 3.78 & 114 \\
\hline & IV-1 & 17.7 & 5.31 & 3.33 & 124 \\
\hline & IV-2 & 19.5 & 5.00 & 3.90 & 98 \\
\hline & IV-3 & 16.7 & 3.80 & 4.39 & 92 \\
\hline Mean \pm SD & & $18.4 \pm 1.3^{*}$ & $4.8 \pm 0.6$ & $3.9 \pm 0.4^{\ddagger}$ & $107 \pm 13$ \\
\hline \multirow[t]{3}{*}{ Heterozygous for intron mutation } & III-9 & 23.2 & 1.92 & 12.10 & 78 \\
\hline & III-10 & 19.0 & 2.52 & 7.55 & 119 \\
\hline & III-11 & 16.9 & 2.90 & 5.82 & 93 \\
\hline Mean \pm SD & & $19.7 \pm 2.6^{\S}$ & $2.5 \pm 0.4^{\|}$ & $8.5 \pm 2.6$ & $97 \pm 17$ \\
\hline \multirow[t]{6}{*}{ Normal } & III-4 & 29.3 & 4.87 & 6.02 & 98 \\
\hline & III-7 & 28.0 & 4.40 & 6.36 & 115 \\
\hline & III-8 & 28.8 & 4.81 & 5.99 & 115 \\
\hline & III-12 & 34.1 & 4.55 & 7.48 & 144 \\
\hline & III-13 & 23.2 & 3.51 & 6.60 & 122 \\
\hline & III-14 & 29.6 & 4.24 & 6.97 & 192 \\
\hline Mean \pm SD & & $28.8 \pm 3.2$ & $4.4 \pm 0.5$ & $6.6 \pm 0.5$ & $131 \pm 30$ \\
\hline
\end{tabular}

The status of family members was determined by DNA analysis. LCAT activity, LCAT concentration and CER were determined in whole plasma samples. Data of heterozygotes for the T123I mutation or intron base substitution were compared with unaffected family members using the Student's $t$ test: $* P<0.0005 ;{ }^{\ddagger} P<0.0001 ;{ }^{\circledR} P<0.007 ;{ }^{\|} P<0.0008$.

verse transcribed mRNA isolated from both cell lines and PCR amplified a region that encompassed intron 4 of the LCAT mRNA molecule using primers complementary to sequences in exons 3 and 5 (Fig. $3 \mathrm{~A}$ ). We identified LCAT mRNA of normal size (309 bp) from the LCAT-Int4-WT cell line but exclusively mutant mRNA (392 bp) from the LCAT-Int4-MUT cell line (Fig. 3 B). Direct sequencing of the 309 bp PCR product showed normal LCAT cDNA sequence whereas sequence analysis of the 392 bp product revealed the presence of unspliced intron 4 including the T-C base substitution (Fig. $3 B$ ).

Analysis of LCAT mRNA of the index patient. By performing RT-PCR on mRNA isolated from leukocytes of the index patient, we obtained approximately equal quantities of a product of normal size (309 bp) and a larger mutant product of 392 bp (Fig. 3 C). Separate sequence analysis of the PCR-products revealed that the smaller product exclusively contained the Ile123 defect while the larger DNA fragment contained intron 4 with the intron mutation and exclusively encoded for Thr at position 123 (Fig. 2 C). A third PCR product of $\sim 500$ bp was likely to be amplified from either genomic DNA or premRNA since its size did fit the size of a DNA fragment containing introns 3 and 4 (Fig. $3 A$ ).

\section{Discussion}

The LCAT gene encodes a plasma glycoprotein which plays a key role in the metabolism of HDL (24). Mutations in this gene underlie HDL deficiency syndromes which are inherited in an apparently autosomal recessive manner (25-27). A large number of LCAT gene defects result in a complete loss of LCAT activity which is associated with classical LCAT deficiency $(25,28,29)$ whereas other defects result in only a partial loss on enzyme activity; this class of defects cause the FED phenotype (1-4).

We have studied a kindred in which three sisters presented with dense corneal opacities and very low plasma HDL-cholesterol, features which are typical of FED. Biochemical analysis revealed that in addition to low normal CER, plasma LCAT of the three probands was not active against HDL-analogues whereas it retained activity against endogenous lipoproteins. These characteristics are indeed indicative of FED.

Subsequent sequence analysis of the LCAT gene of the probands initially revealed heterozygosity for a missense mutation (T123I), which is known to underlie FED $(1,3)$. A second defect was found only after extending our search for mutations further into non-coding regions of the gene. We identified heterozygosity for a $\mathrm{T}$ to $\mathrm{C}$ nucleotide substitution 22 bases upstream of the acceptor splice site of intron 4. DNA analysis of family members revealed heterozygotes for either mutation which proved that the two mutations were located on different alleles. These results showed the segregation of compound heterozygosity for the T123I defect and the intron mutation with the FED phenotype in the three sisters. Furthermore, heterozygous carriers of either defect were shown to exhibit 
A

LCAT CDNA in pNUT expression vector:

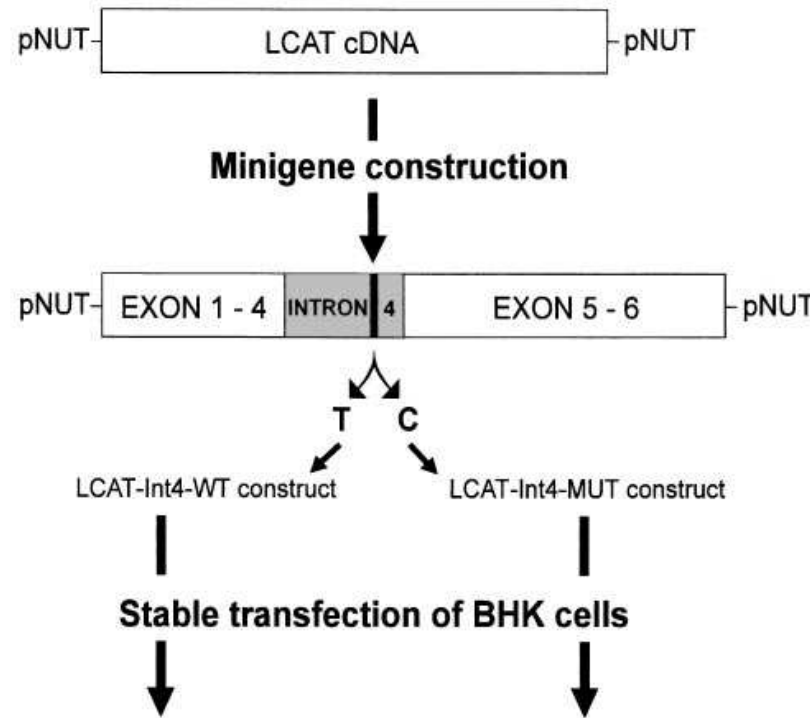

LCAT activity in culture medium

$8.0 \pm 0.5 \mathrm{nmol}$ free cholesterol esterified $/ \mathrm{ml} / \mathrm{hr}$

No detectable LCAT activity in culture medium

B

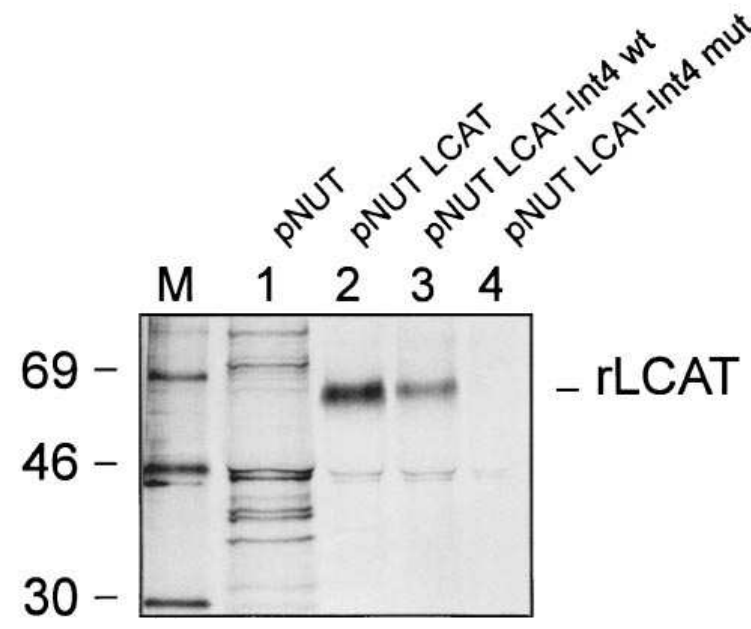

Figure 2. LCAT minigenes, stable transfection and in vivo labeling. $(A)$ A schematic representation of the LCAT minigene constructs which were used for stable transfections of BHK cells. In contrast to the LCAT-Int4-WT cell line, we could not detect LCAT activity in the culture medium harvested from the LCAT-Int4-MUT cell line. $(B)$ Results of an in vivo labeling experiment: lane 1 shows the absence of rLCAT in the medium of BHK cells transfected with an empty pNUT vector. Lane 2 shows rLCAT of $60-67 \mathrm{kD}$ produced by BHK cells transfected with pNUT containing full-length LCAT cDNA. Whereas the LCAT-Int4-WT cell line also secreted rLCAT (lane 3), the LCAT-Int4-MUT cell line did not express LCAT (lane 4).

different characteristics. In addition to differences in TC and LDL-cholesterol levels, carriers of the intron mutation exhibited highly significantly reduced LCAT concentrations as compared to T123I carriers. The latter suggested that the intron defect was associated with abnormal gene expression and/or enhanced protein degradation.
To investigate the hypothesis whether the intron mutation causes a change in the expression of the allele, we stably transfected BHK cells with LCAT minigenes which contained intron 4 with or without the mutation. Initial experiments revealed the lack of synthesis/secretion of LCAT protein by only the cells which were transfected with the mutant minigene while further assessment of the effect of this mutation on LCAT expression clearly showed that the intron mutation resulted in complete intron retention. In addition, these experiments showed that no additional defects in the LCAT gene were required to result in abnormal mRNA processing since the intron retention was shown to result from the presence of this nucleotide substitution only. Since the unspliced intron in the mutant LCAT transcript contains a premature stopcodon, we expected the synthesis of a truncated LCAT protein of $\sim 28 \mathrm{kD}$ by the cell line transfected with the mutant minigene. Although we identified such a protein band after transient transfection of COS1-cells with this mutant construct (data not shown), we did not detect this truncated protein in the medium harvested from the respective BHK cell line which could be due to enhanced catabolism of the mutant protein.

These in vitro observations indicate that the intron mutation is causative for the half normal LCAT concentration as observed in heterozygous carriers. Previously reported mutations in or near putative branchpoint regions of human premRNA were shown to be associated with the use of alternative splice sites $(9,30)$, enhanced efficiency of splicing (31) or exon skipping (32). We investigated, therefore, whether the observed intron retention also occurred in our index patient and identified two LCAT mRNA species in her leukocytes: a product of a size that would be expected after correct splicing of intron sequence, and a larger mutant product. The compound heterozygosity of the patient for both the T123I defect and the intron mutation enabled us to differentiate between the two LCAT alleles: the smallest product exclusively contained the allele encoding the missense mutation (Ile at position 123) while the other DNA fragment contained intron 4 with the intron mutation and exclusively encoded for Thr at this position. These results, which are in agreement with our in vitro data, clearly demonstrated that the intron mutation results in fully abnormal LCAT mRNA processing in vivo.

The finding that the intron mutation results in a null allele helped us to interpret the differences in lipids, lipoproteins and LCAT-related parameters when comparing heterozygotes for the intron mutation with heterozygous carriers of the T123I defect since the latter mutation is associated with a much milder effect on LCAT expression $(1,3,23)$. Carriers of the intron mutation can now be defined as heterozygotes for classic LCAT deficiency whereas carriers of the T123I defect can be categorized as heterozygotes for FED.

To explain the molecular background to the observed intron retention we propose the following mechanism: As already indicated, lariat formation is mediated by an adenosine residue in the context of a branchpoint consensus sequence that can basepair with U2snRNA $(5,7,8)$. The mutated nucleotide in intron 4 of the LCAT gene resides in a sequence that exactly matches the mammalian consensus branchpoint sequence. It concerns the substitution of a highly conserved $U$ for a $\mathrm{C}$, two nucleotides upstream of the putative branchpoint adenosine (Fig. $4 A$ ). Query et al. (8) has proposed that the bulging of the $\mathrm{A}$, which is the result of branch region basepairing with U2snRNA, is required for its usage in the branching 
A

\section{- LCAT genomic DNA}

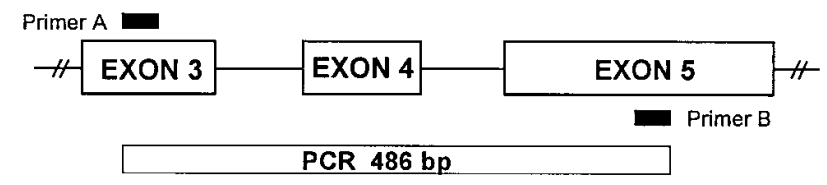

- Mutant LCAT-mRNA

\begin{tabular}{l|l|l|l|}
\hline EXON 3 & EXON 4 \\
\hline
\end{tabular}

\section{- Wild-type LCAT-mRNA}

\begin{tabular}{c}
\begin{tabular}{l|l|l|l}
\hline EXON 3 & EXON 4 & EXON 5 & \\
\hline
\end{tabular} \\
PCR 309 bp \\
\hline
\end{tabular}

B

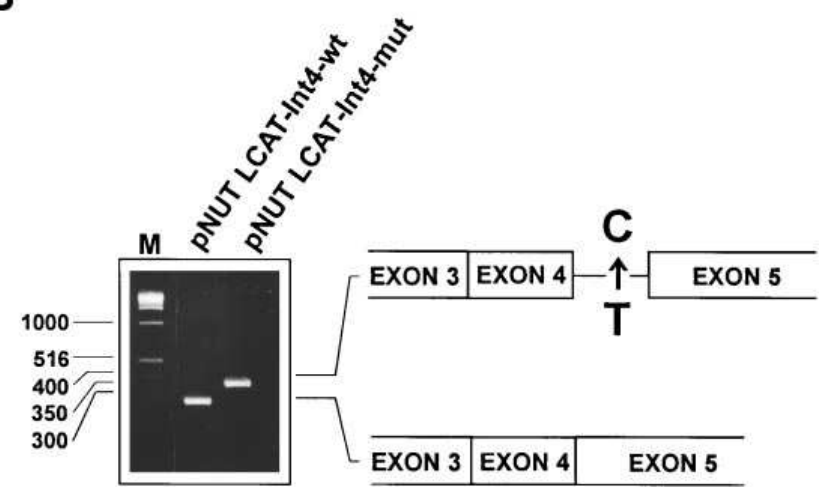

C

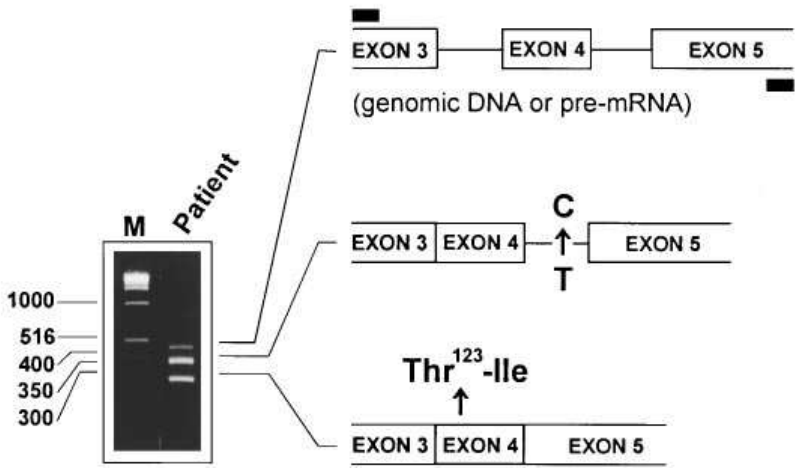

Figure 3. RT-PCR. (A) Schematic representation of the RT-PCR strategy. The use of primers A and B in the PCR reaction results in the generation of easily discernible DNA fragments that are amplified from the LCAT gene, LCAT mRNA which contains intron 4 and wild-type LCAT mRNA, respectively. (B) The results of RT-PCR analysis using mRNA isolated from both minigene cell lines. Each
A

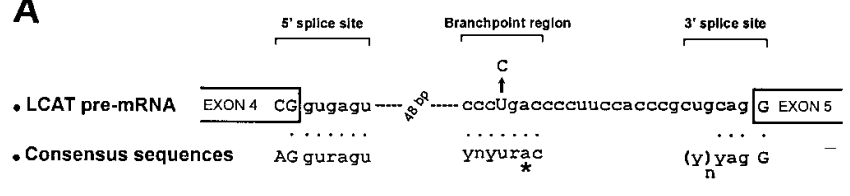

B

- Human U2snRNA branchpoint interaction 3 - AUGAUG - 5, sequence*

- Putative interaction of U2snRNA with the
branchpoint region in wild-type intron 4
of LCAT pre-mRNA

$5 \cdot-\operatorname{CCCUGC}-3$

3.-AUGAUG- 5 ,

U2 snRNA

\begin{abstract}
- Putative affected interaction of U2snRNA with the branchpoint region of mutant pre-mRNA
\end{abstract}

$$
\begin{gathered}
5^{\prime}-\mathrm{CCC}^{\mathrm{CGA}} \mathrm{C}-3^{\prime} \\
3^{\prime}-\mathrm{AUGAUG}-5^{\prime} \\
\text { U2 snRNA }
\end{gathered}
$$

Figure 4. LCAT pre-mRNA and putative interaction with U2snRNA. (A) A schematic representation of intron 4 of LCAT premRNA of which both the $3^{\prime}$-splice site, $5^{\prime}$-splice site and the putative lariat branchpoint region almost completely match the mammalian consensus sequences (the corresponding bases are indicated by dots). Furthermore, it shows that the $\mathrm{T}$ to $\mathrm{C}$ nucleotide substitution (indicated by an arrow) concerns a thymine residue which is highly conserved in the mammalian branchpoint consensus sequence. The adenosine residue which is required for the first cleavage-ligaton step of the splicing reaction (8) is marked with an asterisk. $\mathrm{R}$ is any purine, $\mathrm{Y}$ is any pyrimidine. $(B)$ A schematic representation of the putative interaction of human U2snRNA with both the wild-type and mutated lariat branchpoint region of intron 4 of the LCAT pre-mRNA. The mutated nucleotide is denoted in bold. *The human U2snRNA branchpoint interaction sequence was derived from the yeast branchpoint interaction (5) region and the human U2snRNA sequence (8, $34,35)$.

reaction. Using this concept, it is attractive to assume that the mutation causes intron retention as the result of interference with the binding of U2snRNA to the branchpoint sequence and, consequently, with proper bulging of the adenosine residue (Fig. $4 B$ ).

In conclusion, we demonstrated that a point mutation in a lariat branchpoint consensus sequence causes intron retention and therefore results in a null allele in three subjects with FED. This finding indicates that the mechanisms of splicing as deduced from yeast also play an important role in humans. To

cell line produced one species of LCAT mRNA. Sequencing of the PCR products revealed that the LCAT-Int4-WT cell line only produced wild-type LCAT mRNA (lane 1) while we exclusively identified mutant LCAT mRNA containing intron 4 from the LCAT-Int4MUT cell line (lane 2). (C) Lane 2 shows three RT-PCR products obtained from mRNA isolated from leukocytes of a compound heterozygous patient: a 500-bp DNA fragment (not sequenced because of low mass) which we speculate to be amplified from either genomic DNA or pre-mRNA. The sizes of the two other products correlated with LCAT mRNA containing intron 4 (392 bp) and normally spliced mRNA (309 bp). Separate sequence analysis of the PCR products revealed that the larger band contained intron 4 (with the $\mathrm{T}$ to $\mathrm{C}$ mutation) and the smaller band represented normally spliced mRNA that exclusively contained the missense mutation (T123I). 
ensure effective and fast screening for mutations, to circumvent extensive sequencing of noncoding DNA and to diminish the chance of missing causal defects such as described in this report, we would like to suggest the following strategy: Isolation of mRNA from leukocytes of the patient, subsequent first-strand cDNA synthesis and highly specific touch-down RT-PCR-amplification (19) of distinct regions of the target mRNA followed by direct solid-phase automated sequencing of RT-PCR products in addition to fragment-size analysis. Since this method proved to be successful for the LCAT gene which expression is primarily confined to the liver (33), we think that our strategy is well-suited for the amplification of various species of mRNA. Furthermore, we demonstrated that easily accessible leukocytes can replace organ biopsies in order to obtain mRNA sequence information.

\section{Acknowledgments}

We are indebted to all members of the family investigated whose cooperation enabled us to perform this study. Furthermore, we wish to thank Janine Senz, Gert-Jan Botma, and Milada Dobiasova for their excellent technical assistance and Helmy Brink, Alice van Zijl, and Björn Groenemeyer for their help in obtaining blood samples from the investigated kindred.

The project was supported by grants from the Dutch Heart Foundation (nr. 89201), the Medical Research Council of Canada and the Deutsche Foschungsgemeinschaft (SU179/1-1) and National Institutes of Health grant HL-30086. Dr. J.J.P. Kastelein is a clinical investigator of the Dutch Heart Foundation.

\section{References}

1. Klein, H.G., P. Lohse, P.H. Pritchard, D. Bojanovski, H. Schmidt, and H.B. Brewer, Jr. 1992. Two different allelic mutations in the lecithin-cholesterol acyltransferase gene associated with the fish-eye syndrome. Lecithin-cholesterol acyltransferase (Thr123-Ile) and lecithin-cholesterol acyltransferase (Thr347Met). J. Clin. Invest. 89:499-506.

2. Skretting, G., and H. Prydz. 1992. An amino acid exchange in exon I of the human lecithin: cholesterol acyltransferase (LCAT) gene is associated with fish-eye disease. Biochem. Biophys. Res. Commun. 182:583-587.

3. Funke, H., A. von Eckardstein, P.H. Pritchard, J.J. Albers, J.JP. Kastelein, C. Droste, and G. Assmann. 1991. A molecular defect causing fish eye disease: An amino acid exchange in lecithin-cholesterol acyltransferase (LCAT) leads to the selective loss of alpha-LCAT activity. Proc. Natl. Acad. Sci. USA. 88:4855-4859.

4. Kuivenhoven, J.A., E.J.G.M. van Voorst tot Voorst, H. Wiebusch, S.M. Marcovina, H. Funke, G. Assmann, P.H. Pritchard, and J.J.P. Kastelein. 1995. A unique genetic and biochemical presentation of fish-eye disease. J. Clin. Invest. 96:2783-2791.

5. Madhani, H.D., and C. Guthrie. 1994. Dynamic RNA-DNA interactions in the spliceosome. Аnпи. Rev. Genet. 28:1-26.

6. Lamond, A.I. 1993. The Spliceosome. BioEssays. 15:595-603.

7. Sharp, P. 1987. Splicing of messenger RNA precursors. Science (Wash. DC). 235:767-771.

8. Query, C.C., M.J. Moore, and P.A. Sharp. 1994. Branch nucleophile selection in pre-mRNA splicing: evidence for the bulged duplex model. Genes \& Dev. 8:587-597.

9. Rosenthal, A., M. Jouet, and S. Kenwrick. 1992. Aberrant splicing of neural cell adhesion molecule L1 mRNA in a family with X-linked hydrocephalus. Nat. Genet. 2:107-112.

10. Southern, E.M. 1975. Detection of specific sequences among DNA fragments separated by gel electrophoresis. J. Mol. Biol. 98:503-517.

11. Friedewald, W.T., R.I. Levy, and D.S. Frederickson. 1972. Estimation of the concentration of low-density lipoprotein in plasma, without use of the pre- parative ultracentrifuge. Clin. Chem. 18:499-502.

12. Frohlich, J., R. McLeod, P.H. Pritchard, J. Fesmire, and W. McConathy. 1988. Plasma lipoprotein abnormalities in heterozygotes for familial lecithin cholesterol acyltransferase deficiency. Metabolism. 37:3-8.

13. Albers, J.J., J.C. Adolphson, and C.H. Chen. 1981. Radioimmunoassay of human lecithin-cholesterol acyltransferase. J. Clin. Invest. 67:141-148.

14. Stokke, K.T., and K.R. Norum. 1971. Determination of LCAT in human blood plasma. Scand. J. Clin. Lab. Invest. 27:21-27.

15. Dobiasova, M., and M. Schutzova. 1986. Cold labelled substrate and estimation of cholesterol esterification rate in lecithin cholesterol acyltransferase radioassay. Physiol. Bohemoslov. 35:319-327.

16. Hultman, T., S. Stahl, E. Homes, and M. Uhlen. 1989. Direct solid phase sequencing of genomic and plasmid DNA using magnetic beads as a solid support. Nucleic Acids. Res. 17:4937-4946.

17. McLean, J., K. Wion, D. Drayna, C. Fielding, and R. Lawn. 1986. Human lecithin cholesterol acyltransferase gene: complete gene sequence and sites of expression. Nucleic Acids. Res. 14:9397-9406.

18. Chou, Q., M. Russell, D.E. Birch, J. Raymond, and W. Bloch. 1992. Prevention of pre-PCR mis-priming and primer dimerization improves low-copynumber amplifications. Nucleic Acids. Res. 20:1717-1723.

19. Don, R.H., P.T. Cox, B.J. Wainwright, K. Baker, and J.S. Mattick. 1991. Touchdown PCR to circumvent spurious priming during gene amplification. Nucleic Acids. Res. 19:4008.

20. Palmiter, R.D., R.R. Behringer, C.J. Quaife, F. Maxwell, I.H. Maxwell, and R.L. Brinster. 1987. Cell lineage ablation in transgenic mice by cell-specific expression of a toxin gene. Cell. 50:435-443.

21. Funk, W.D., R.T.A. MacGillivray, A.B. Mason, S.A. Brown, and R.C. Woodworth. 1990. Expression of the amino-terminal half-molecule of human serum transferring in cultured cells and characterization of the recombinant protein. Biochemistry. 29:1654-1660.

22. Hill, J.S., K.O., X. Wang, S. Paranjape, D. Dimitrijevich, A.G. Lacko, and P.H. Pritchard. 1993. Expression and characterization of recombinant human lecithin: cholesterol acyltransferase. J. Lipid Res. 34:1245-1251.

23. O, K., J.S. Hill, X. Wang, and P.H. Pritchard. 1993. Recombinant lecithin:cholesterol acyltransferase containing a Thr123 to Ile mutation esterifies cholesterol in low density lipoprotein but not in high density lipoprotein. $J$. Lipid Res. 34:81-88.

24. Jonas, A. 1991. Lecthin-cholesterol acyltransferase in the metabolism of high-density lipoproteins. Biochim. Biophys. Acta. 1084:205-220.

25. McIntyre, N. 1988. Familial LCAT deficiency and Fish-Eye Disease. $J$. Inherit. Metab. Dis. 1:45-56.

26. Assmann, G., A. von Eckardstein, and H. Funke. 1991. Lecithin:cholesterol acyltransferase deficiency and fish-eye disease. Curr. Opin. Lipidol. 2:110117

27. Norum, K.R., E. Gjone, and J.A. Glomset. 1989. Familial lecithin:cholesterol acyltransferase deficiency, including fish eye disease. In The Metabolic Basis of Inherited disease. C.R. Scriver, A.L. Beaudet, W.S. Sly, and D. Valle, editors. McGraw-Hill, Inc., New York. 1181-1194.

28. Gotoda, T., N. Yamada, T. Murase, M. Sakuma, N. Murayama, H. Shimano, K. Kozaki, J.J. Albers, Y. Yazaki, and Y. Akanuma. 1991. Differential phenotypic expression by three mutant alleles in familial lecithin:cholesterol acyltransferase deficiency. Lancet. 338:778-781.

29. Funke, H., A. von Eckardstein, P.H. Pritchard, A.E. Hornby, H. Wiebusch, C. Motti, M.R. Hayden, C. Dachet, B. Jacotet, U. Gerdes, et al. 1993. Genetic and phenotypic heterogeneity in familial lecithin: cholesterol acyltransferase (LCAT) deficiency. Six newly identified defective alleles further contribute to the structural heterogeneity in this disease. J. Clin. Invest. 91:677-683.

30. Estes, P.A., N.E. Cooke, and S.A. Liebhaber. 1990. A difference in the splicing patterns of the closely related normal and variant human growth hormone gene transcripts is determined by a minimal sequence divergence between two potential splice-acceptor sites. J. Biol. Chem. 265 (32):19863-19870.

31. Rautmann, G., and R. Breathnach. 1985 A role for branchpoints in splicing in vivo. Nature (Lond.). 315:430-432.

32. Nakahashi, Y., H. Fujita, S. Taketani, N. Ishida, Y. Kappas, and S Sassa. 1992. The molecular defect of ferrochelatase in a patient with erythropoietic protoporphyria. Proc. Natl. Acad. Sci. USA. 89:281-285.

33. McLean, J., C. Fielding, D. Drayna, H. Dieplinger, B. Baer, W. Kohr, W. Henzel, and R. Lawn. 1986. Cloning and expression of human lecithin:cholesterol acyltransferase cDNA. Proc. Natl. Acad. Sci. USA. 83:2335-2339.

34. van Arsdell, S.W., and A.M. Weiner. 1984. Human genes for U2 small nuclear RNA are tandemly repeated. Mol. Cell. Biol. 4(3):492-499.

35. Guthrie, C., and B. Patterson. 1988. Spliceosomal snRNAs. Annu. Rev. Genet. 22:387-419. 